\title{
Role of the Nucleus Raphe Magnus in Antinociception Produced by ABT-594: Immediate Early Gene Responses Possibly Linked to Neuronal Nicotinic Acetylcholine Receptors on Serotonergic Neurons
}

\author{
R. Scott Bitner, Arthur L. Nikkel, Peter Curzon, Stephen P. Arneric, Anthony W. Bannon, and \\ Michael W. Decker
}

Neurological and Urological Diseases Research, Pharmaceutical Products Division, Abbott Laboratories, Abbott Park, Illinois 60064-3500

Recently, a novel cholinergic channel modulator, $(R)-5-(2-$ azetidinylmethoxy)-2-chloropyridine (ABT-594), was shown to produce potent analgesia in a variety of rodent pain models when administered either systemically or centrally into the nucleus raphe magnus (NRM). The purpose of the present study was to investigate the possible supraspinal contribution of ABT-594 by assessing its ability to induce expression of the immediate early gene c-fos, a biochemical marker of neuronal activation, in the NRM of rats. Putative serotonergic neurons in the NRM, a medullary nucleus proposed to be involved in descending antinociceptive pathways, were identified immunohistochemically using a monoclonal antibody (mAb) against tryptophan hydroxylase. ABT-594 (0.03-0.3 $\mu \mathrm{mol} / \mathrm{kg}$, i.p.) produced a dose-dependent induction of Fos protein that was blocked by the central nicotinic acetylcholine receptor (nAChR) antagonist mecamylamine (5 $\mathrm{mol} / \mathrm{kg}$, i.p.) but not by the pe- ripheral $\mathrm{nAChR}$ antagonist hexamethonium (15 $\mu \mathrm{mol} / \mathrm{kg}$, i.p.). Immunohistological studies using mAb 299 revealed the expression of $\alpha 4$-containing $\mathrm{nAChRs}$ in the NRM. The $\alpha 4$ immunostaining was dramatically reduced by pretreating (30 d) animals with the serotonin neurotoxin 5,7-dihydroxytryptamine (5,7-DHT), which was previously shown to substantially attenuate the antinociceptive actions of ABT-594. In a double immunohistochemical labeling experiment, coexpression of the serotonin marker tryptophan hxdroxylase and the $\alpha 4 \mathrm{nAChR}$ subunit in NRM neurons was observed. These results suggest that the analgesic mechanism of ABT-594 may in part involve the activation of the NRM, a site where $\alpha 4$-containing nAChRs are expressed by serotonergic neurons.

Key words: ABT-594; nucleus raphe magnus; c-fos expression; nicotinic antagonism; serotonin; $\alpha 4$-containing nicotinic acetylcholine receptor; antinociception
Antinociception produced by nicotine was first reported $>60$ years ago (Davis et al., 1932), yet the use of nicotinic acetylcholine receptor (nAChR) agonists as viable analgesics has received limited consideration. However, the discovery of epibatidine, a potent nAChR agonist with analgesic properties (for review, see Sullivan and Bannon, 1996) and the cloning of neuronal nAChR subunits (Sargent, 1993; McGehee and Role, 1995) have provided a stronger basis for investigation of analgesic nicotinics that act more selectively in the CNS. Indeed, the novel $\mathrm{nAChR}$ agonist (R)-5-(2-azetidinylmethoxy)-2-chloropyridine (ABT-594) was recently reported to produce antinociception equal in efficacy to morphine in a variety of rodent pain models after systemic and central administration (Bannon et al., 1998).

The nucleus raphe magnus (NRM) is a serotonergic nucleus located in the rostral ventromedial medulla of the brainstem. Axons of the NRM project to the spinal cord (Bowker et al., 1982), terminating primarily in the dorsal horn (Jones and Light, 1990). Brainstem nuclei that project to the dorsal horn of the spinal cord can function to inhibit afferent nociceptive transmission (Basbaum and Fields, 1979; Willis, 1988; Sandkuhler, 1996).

\footnotetext{
Received Jan. 7, 1998; revised April 20, 1998; accepted April 24, 1998.

This research work was supported by Abbott Laboratories.

Correspondence should be addressed to Dr. R. Scott Bitner, Neurological and Urological Diseases Research, Pharmaceutical Products Division, Abbott Laboratories, Building AP9A-LL (D-47W), Abbott Park, IL 60064-3500.

Copyright (C) 1998 Society for Neuroscience $0270-6474 / 98 / 185426-07 \$ 05.00 / 0$
}

Activation of these descending antinociceptive pathways may be triggered by physiological stimuli (Millan et al., 1980) as well as by pharmacological agents (Gogas et al., 1991). Antinociception involving the NRM has been studied after either electrical stimulation or direct administration of pharmacological agents (Proudfit and Anderson, 1975; Oleson et al., 1978; Brodie and Proudfit, 1986).

Iwamoto (1991) reported that nicotine injected directly into the NRM produced antinociception in rat models of thermal pain. Similarly, we demonstrated that an intra-NRM injection of ABT594 produced antinociception in a thermal model of acute and a chemical model of persistent pain (Curzon et al., 1997; Bannon et al., 1998). Mapping studies in the rat have revealed the expression of different $\mathrm{nAChR}$ subunits in various brainstem regions at the RNA (Wada et al., 1989) and protein (Swanson et al., 1987) levels, supporting an nAChR-mediated mechanism of antinociception involving a supraspinal site of action. However, to date there are no reports specifically identifying $\mathrm{nAChR}$ expression in the NRM.

The purpose of the present study was to further investigate the possible contribution of the NRM to antinociception produced by systemic ABT-594. Expression of the immediate early gene c-fos is triggered by a variety of depolarizing events (Morgan et al., 1987; Sagar et al., 1988; Morgan and Curran, 1991), including nAChR activation (Greenberg et al., 1986). We previously demonstrated that an antinociceptive dose of ABT-594 given system- 
ically produced an increase in c-fos expression in the NRM of rats (Bannon et al., 1998). Here, further studies were conducted to determine the ability of ABT-594 to induce the expression of Fos protein in the NRM as an in situ marker of nAChR activation. Effects of nAChR antagonism on ABT-594-induced c-fos expression were also assessed. In addition, the expression of the $\alpha 4$ subunit of the nAChR in the NRM was immunohistochemically evaluated. To specifically test the possibility that $\alpha 4$-containing nAChRs are expressed by serotonin-containing neurons, we also examined the effects of a local serotonergic lesion on $\alpha 4$ expression in the NRM and assessed coexpression by double immunohistochemical labeling.

\section{MATERIALS AND METHODS}

Animals and experimental treatments. Male Sprague Dawley rats (Charles River Laboratories, Portage, MI) weighing 350-400 gm were used. The animals were group-housed in an American Association for the Accreditation of Laboratory Animal Care-approved facility at Abbott Laboratories (Abbott Park, IL) in a temperature-regulated environment with lights on between 7:00 A.M. and 8:00 P.M.. All experimental procedures involving animals were conducted under protocols approved by Abbott's Institutional Animal Care and Use Committee.

Rats received a single intraperitoneal injection of either saline (1 $\mathrm{ml} / \mathrm{kg})$ or ABT-594 $(0.03,0.1$, or $0.3 \mu \mathrm{mol} / \mathrm{kg})$ or, in other studies, were pretreated with either the nAChR antagonists hexamethonium (15 $\mu \mathrm{mol} / \mathrm{kg}$, i.p.) or mecamylamine $(5 \mu \mathrm{mol} / \mathrm{kg}$, i.p.) followed $15 \mathrm{~min}$ later by ABT-594 $(0.3 \mu \mathrm{mol} / \mathrm{kg}$, i.p). Two hours after drug treatment the animals were deeply anesthetized with pentobarbital and perfused through the aorta with buffered saline ( $3 \mathrm{~min}, 25 \mathrm{ml} / \mathrm{min}$ ) followed by $10 \%$ formalin $(12 \mathrm{~min}, 30 \mathrm{ml} / \mathrm{min})$. The brains were removed and post-fixed in either $10 \%$ formalin or $20 \%$ sucrose PBS for $12-24 \mathrm{hr}$ before immunohistochemical assessment.

Rats were anesthetized intraperitoneally with $55 \mathrm{mg} / \mathrm{kg}$ sodium pentobarbital and placed in a David Kopf student stereotaxic instrument (Tujunga, CA) with the skull on an even horizontal plane. Coordinates for intra-NRM injections from intra-aural zero were anteroposterior, $-2.5 \mathrm{~mm}$; mediolateral, $0.0 \mathrm{~mm}$; and dorsoventral $-0.5 \mathrm{~mm}$. Rats were then injected with either PBS or the serotonin neurotoxin 5,7dihydroxytryptamine (5,7-DHT; $3.75 \mathrm{nmol}$ in $0.3 \mu$ l over $60 \mathrm{sec}$ ) using a 31 gauge injector. Thirty days after an intra-NRM injection of 5,7-DHT (or PBS), the animals were anesthetized and perfused, as described above. The ability of an intra-NRM injection of 5,7-DHT to produce a serotonergic lesion was determined by assessing tryptophan hydroxylase immunostaining throughout the NRM.

Compounds. ABT-594 was synthesized (Holladay et al., 1997) at Abbott Laboratories. Mecamylamine hydrochloride, hexamethonium hydrochloride, and 5,7-dihydroxytryptamine creatinine sulfate were obtained from Sigma (St. Louis, MO).

Immunohistochemistry of paraffin sections. After post-fixation in $10 \%$ formalin, brains from saline-treated animals were processed and embedded in paraffin, sectioned $(6 \mu \mathrm{m})$, and mounted on aminosilane-coated glass slides (Newcomer Supply). Specifically, coronal sections from the brainstem that contained the NRM $(-9.3 \mathrm{~mm}$ to $-11.0 \mathrm{~mm}$ from bregma; Paxinos and Watson, 1997) were mounted. The immunohistochemical procedure used consisted of a three-step avidin-biotin complex (ABC)-peroxidase technique. Sections were first deparaffinized through a xylene and graded alcohol series, followed by a $20 \mathrm{~min}$ incubation in blocking serum. The sections were then incubated for $60 \mathrm{~min}$ with a primary antibody $(\mathrm{Ab})$ against tryptophan hydroxylase (mouse monoclonal IgG, $2.3 \mu \mathrm{g} / \mathrm{ml}$; Sigma) or the $\alpha 4$ subunit of the nAChR [rat monoclonal IgG, monoclonal antibody (mAb) 299, $2 \mu \mathrm{g} / \mathrm{ml}$; purchased from $\mathrm{J}$. Lindstrom, University of Pennsylvania]. Sections were next washed in PBS and incubated in a biotinylated secondary Ab solution $(10 \mu \mathrm{g} / \mathrm{ml})$ for $30 \mathrm{~min}$, washed in PBS, and then incubated with $\mathrm{ABC}$ reagent (Vectastain Elite, Vector Laboratories, Burlingame, CA). The sections were visualized by incubation for $2-8 \mathrm{~min}$ in a peroxidase substrate solution (diaminobenzidine) and counterstained with hematoxylin. Sections were examined and photographed with a DMRB light microscope (Leica, Nussloch, Germany).

Double immunohistochemical labeling using Abs against tryptophan hydroxylase and the $\alpha 4 \mathrm{nAChR}$ subunit, described above, was performed using a fluorochrome and biotinylated secondary $\mathrm{Ab}$, respectively. Sec- tions from the NRM of a saline-treated rat were first incubated with the anti-tryptophan hydroxylase $\mathrm{Ab}$ for $90 \mathrm{~min}$ and then washed in PBS and incubated with a fluorescein-conjugated secondary $\mathrm{Ab}(20 \mu \mathrm{g} / \mathrm{ml}$, Vector Laboratories) for $60 \mathrm{~min}$. The sections were then examined and photographed under a fluorescence microscope (excitation filter BP, 450-490 $\mathrm{nm}$; Leica, DMRB). Next, the same sections were incubated with the anti- $\alpha 4 \mathrm{Ab}(\mathrm{mAb} 299)$ overnight at $4^{\circ} \mathrm{C}$. The following day the sections were washed in PBS and incubated for $30 \mathrm{~min}$ with a biotinylated secondary $\mathrm{Ab}(5 \mu \mathrm{g} / \mathrm{ml}$, Vector Laboratories) that was mouse- adsorbed and affinity-purified to prevent cross-reactivity with the primary Ab used in the previous incubation against tryptophan hydroxylase. Finally, the sections were incubated with $\mathrm{ABC}$ reagent, visualized by incubation for $8 \mathrm{~min}$ in a peroxidase substrate solution (diaminobenzidine), and counterstained with hematoxylin. The sections were again examined and photographed under a light microscope (Leica, DMRB) and compared with the previous fluorescent micrographs for double labeling.

Immunohistochemistry of free-floating sections. After overnight incubation in $20 \%$ sucrose-PBS, brains from saline- and ABT-594-treated rats were cut on a cryostat ( $40 \mu \mathrm{m}$ coronal sections). Free-floating sections were immunostained for Fos protein using a three-step ABC-peroxidase technique beginning with a $30 \mathrm{~min}$ incubation with blocking serum. Sections were next incubated with anti-Fos Ab (sheep polyclonal IgG, 1:2000; Genosys) for $48 \mathrm{hr}$ at $4^{\circ} \mathrm{C}$, washed with PBS, and incubated for 1
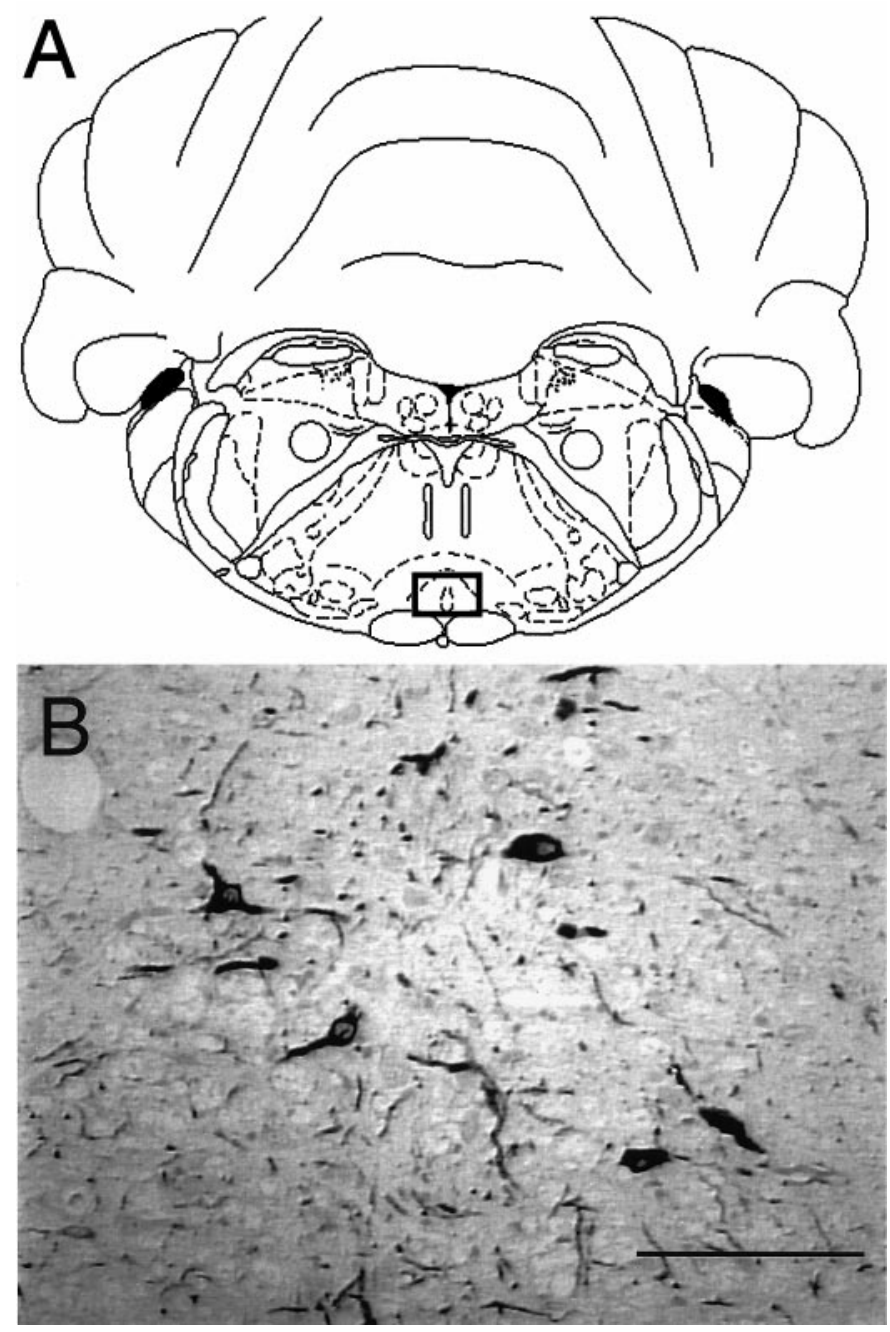

Figure 1. Immunohistochemical identification of the nucleus raphe magnus (NRM). The rat NRM is located (open square) in the rostral ventromedial medulla and is centered just above the pyramidal tract at the base of the brainstem $(A)$ (adapted from Paxinos and Watson, 1997). Serotonergic neurons of the NRM $(B)$ were immunohistochemically identified using an $\mathrm{mAb}$ against tryptophan hydroxylase in a saline-treated rat. Scale bar, $100 \mu \mathrm{m}$. 

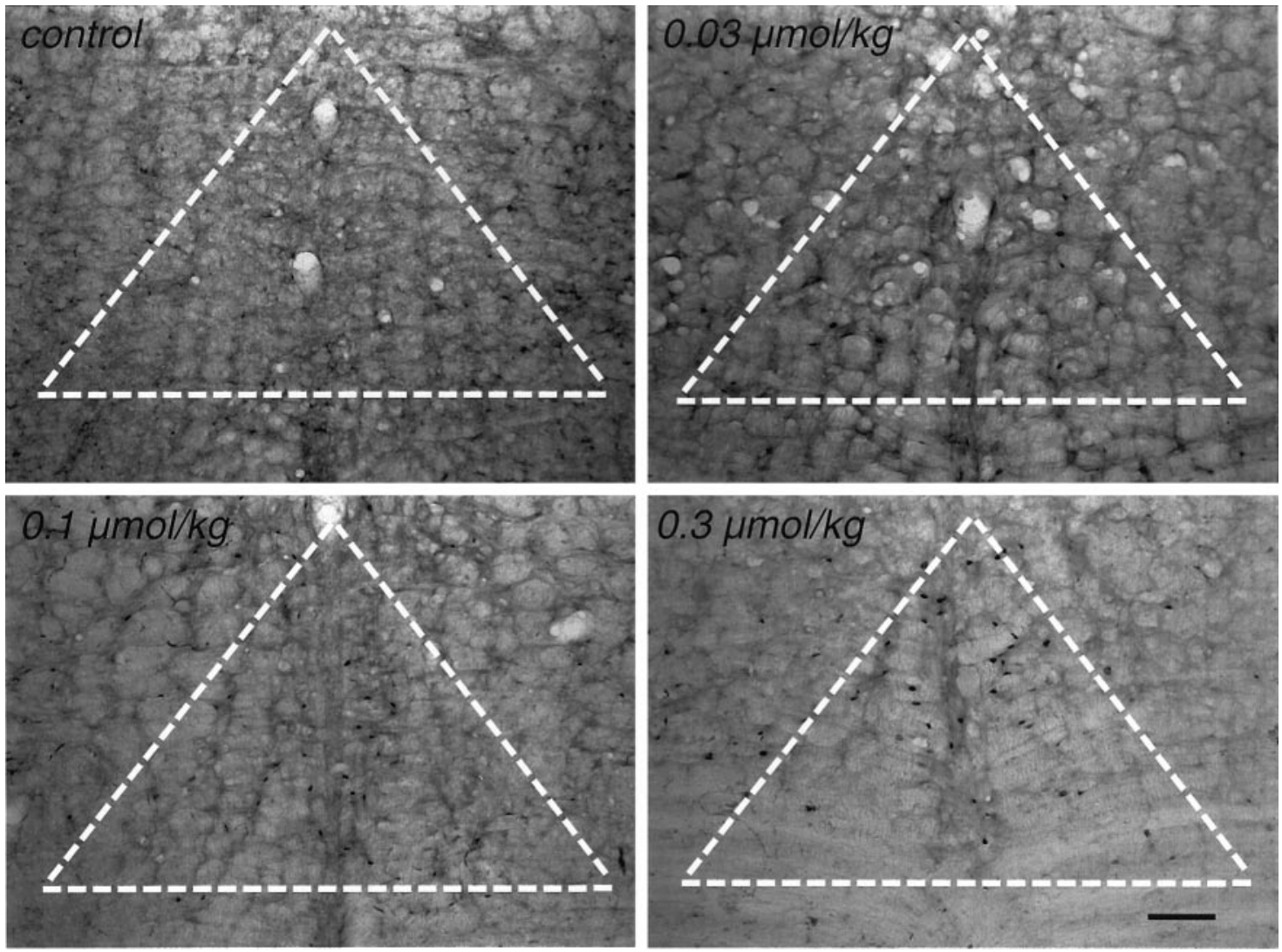

Figure 2. Photomicrographs of Fos protein in the NRM after ABT-594. Induction of c-Fos expression in the NRM of rats is shown 2 hr after systemic administration of ABT-594 at either $0,0.03,0.1$, or $0.3 \mu \mathrm{mol} / \mathrm{kg}$ intraperitoneally. The nuclear immunostaining associated with Fos expression is highest in the $0.3 \mu \mathrm{mol} / \mathrm{kg}$-treated rat. White hatched triangle represents area of NRM analyzed for FLI. Scale bar, $100 \mu \mathrm{m}$.

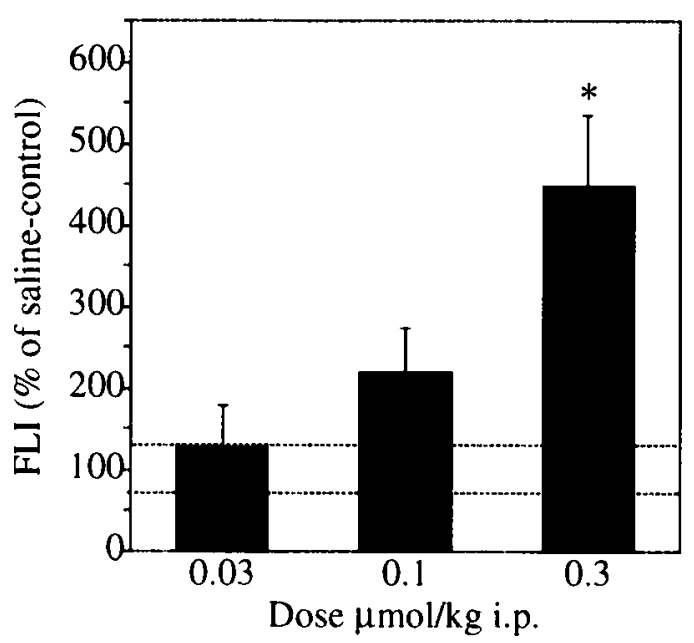

Figure 3. Graphs of ABT-594 Fos protein induction. Systemic administration of ABT-594 (0.03-0.3 $\mu$ mol, i.p.) in rats $(n=6$ per group) produced a dose-dependent induction of Fos expression in the NRM $\left(F_{(3,20)}=7.336 ; p=0.0017\right)$. Fos-like immunoreactivity $(F L I)$ was quantified and expressed as the percent of saline-treated control FLI mean \pm SEM [hatched lines represent \pm control SEM; ${ }^{*} p<0.01$ vs saline-treated rats; protected least significant difference (PLSD) post hoc test].

hr with a biotinylated secondary anti-sheep Ab solution (1:200). Finally, sections were washed in PBS, incubated with ABC reagent (Vector Laboratories), and then developed in a peroxidase substrate solution. The sections were mounted, coverslipped, examined, and photographed with a light microscope (Leica, DMRB). Fos-like immunoreactivity
(FLI) was quantified using an image analysis system (Leica, Quantimet 500) that identified and counted immunostained neurons according to a gray level that was empirically determined before analysis.

Statistics. Data were analyzed using ANOVA followed by Fisher's protected least significant difference (PLSD) post hoc test. Statistical analyses on data were performed using StatView (Abacus Concepts, Calabasas, CA).

\section{RESULTS}

Neurochemical-immunohistochemical identification of the NRM

Studies were conducted to immunohistologically identify the serotonin-containing neurons of the NRM using an antibody against the rate-limiting enzyme of serotonin synthesis, tryptophan hydroxylase. Positive immunostaining was observed centered above the left and right pyramidal tracts in the medial ventral medulla, the location of the NRM (Fig. 1). A similar pattern of staining in the NRM was also observed using a polyclonal $\mathrm{Ab}$ against serotonin that was prevented by preincubation of the primary Ab with $20 \mu \mathrm{g} / \mathrm{ml}$ serotonin (data not shown).

\section{ABT-594-induced Fos expression in the NRM}

The ability of ABT-594 to induce the expression of Fos protein in the NRM was used as an in situ measure of neuronal activation. Two hours after systemic administration of ABT-594 (0.03, 0.1, and $0.3 \mu \mathrm{mol} / \mathrm{kg}$, i.p.), an increase in Fos immunostaining was observed in the NRM (Fig. 2). Fos-like immunoreactivity was quantitated using a Quantimet 500+ image analysis system. ABT-594 produced a dose-dependent induction of FLI in the $\operatorname{NRM}\left(F_{(3,20)}=7.336 ; p=0.0017\right)$, as illustrated in Figure 3 . 


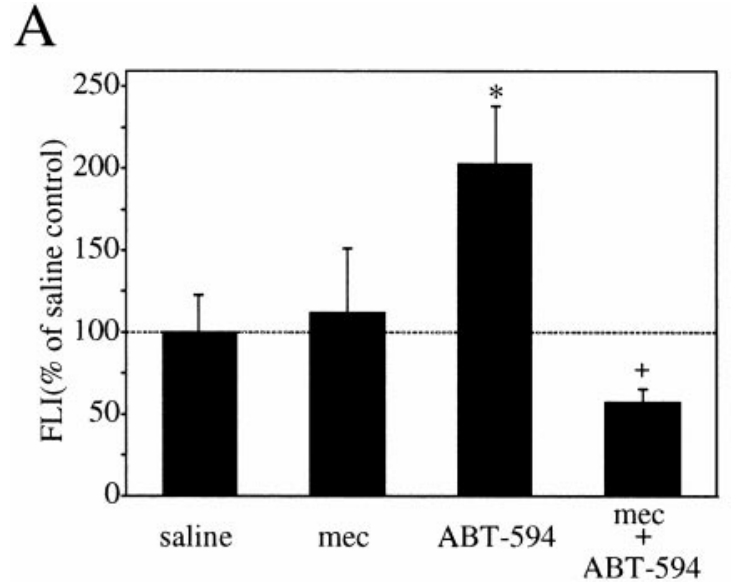

B

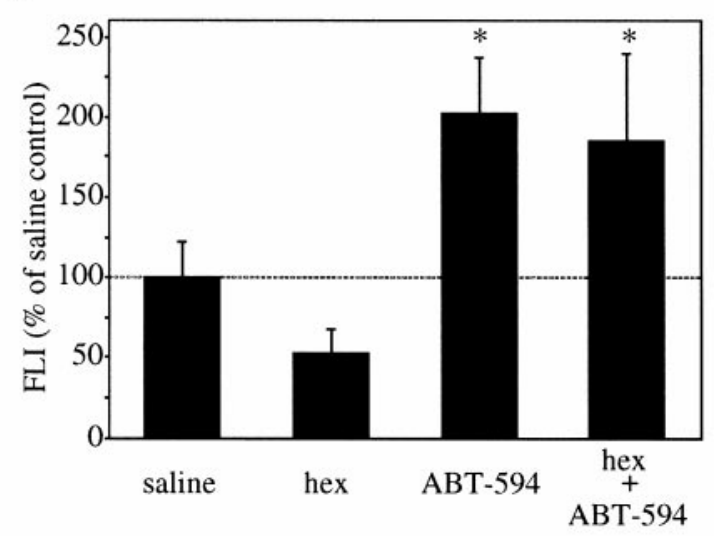

Figure 4. Graphs of ABT-594 Fos protein induction and the effects of nicotinic antagonism. Administration of the nAChR antagonist mecamylamine (5 $\mu \mathrm{mol} / \mathrm{kg}$, i.p.) $15 \mathrm{~min}$ before ABT-594 $(0.3 \mu \mathrm{mol} / \mathrm{kg}$, i.p.) prevents ABT-594-induced Fos expression in the NRM of rats $(n=$ 4-6 per group) $2 \mathrm{hr}$ later $(A)$. Administration of the peripheral nAChR antagonist hexamethonium $(15 \mu \mathrm{mol} / \mathrm{kg}$, i.p. $) 15 \mathrm{~min}$ before ABT-594 $(0.3 \mu \mathrm{mol} / \mathrm{kg}$, i.p. $)$ did not prevent ABT-594-induced Fos expression in the NRM of rats $(n=4-6$ per group) $2 \mathrm{hr}$ later $(B)$. FLI is expressed as the percent of saline control FLI mean \pm SEM $(* p<0.05$ compared with saline-treated rats; $+p<0.05$ as compared with ABT-594-treated rats; PLSD post hoc test).

At the higher $0.3 \mu \mathrm{mol} / \mathrm{kg}$ dose, ABT-594 produced a fourfold increase in Fos expression compared with saline-treated controls $(p<0.01)$.

The effects of nAChR antagonism on ABT-594-induced c-fos expression are summarized in Figure 4. In these experiments, ABT-594 (0.3 $\mu \mathrm{mol} / \mathrm{kg}$, i.p.) produced a significant increase in FLI $(p<0.05)$ that was blocked by pretreatment with the nAChR antagonist mecamylamine $(5 \mu \mathrm{mol} / \mathrm{kg}$, i.p.). In contrast, pretreatment with the peripheral nAChR antagonist hexamethonium (15 $\mu \mathrm{mol} / \mathrm{kg}$, i.p.) did not prevent the expression of Fos produced by ABT-594 $(0.3 \mu \mathrm{mol} / \mathrm{kg})$.

\section{nAChR expression in the NRM}

Immunohistochemical analysis of $\alpha 4$-containing nAChRs in the NRM is summarized in Figure 5. Expression of the $\alpha 4 \mathrm{nAChR}$ was observed in the NRM using mAb 299. At higher magnification, it was evident that the immunostaining was greatest in the soma of the neurons, with the exception of the nucleus, but positive staining was also present in the neuropil. Using a polyclonal $\mathrm{Ab}$ raised against the $\mathrm{C}$ terminus of the $\alpha 4$ subunit, a
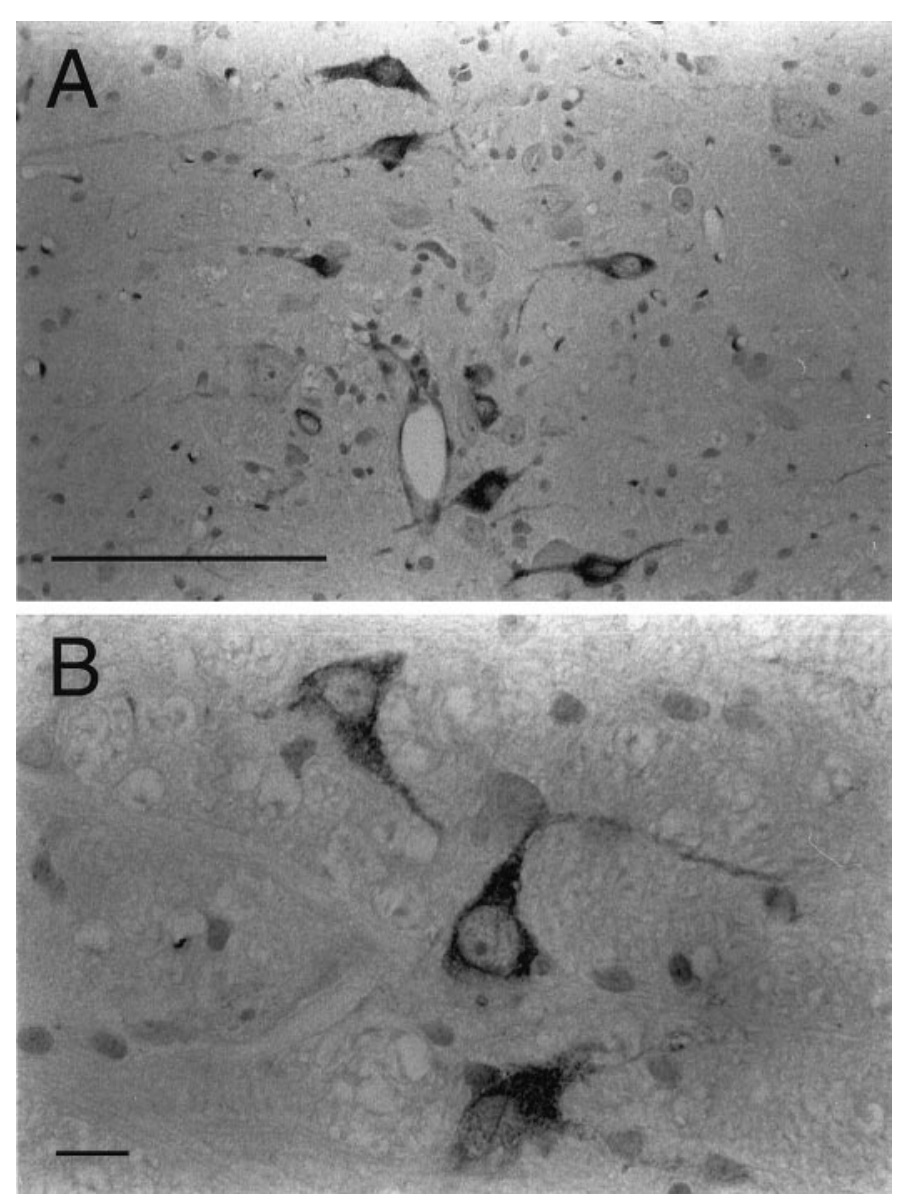

Figure 5. Photomicrographs of the $\alpha 4$ nAChR subunit in the NRM. $\alpha 4$ immunostaining ( $\mathrm{mAb} 299)$ was observed in the NRM $(A)$ of a salinetreated rat. At higher magnification $(B)$, the $\alpha 4$ subunit is seen primarily in the cytosol of the soma. Expression of $\alpha 4$ is also seen, but to a lesser extent, in the neuropil. Scale bars: $A, 100 \mu \mathrm{m} ; B, 10 \mu \mathrm{m}$.

similar pattern of staining compared with mAb 299 was observed and was prevented with preincubation of the peptide $(20 \mu \mathrm{g} / \mathrm{ml})$ used to raise the $\mathrm{Ab}$ (data not shown). Alternatively, there were neurons in the NRM that did not show expression of the $\alpha 4$ subunit.

\section{Intra-NRM 5,7-DHT and nAChR expression}

To examine the effects of a serotonergic NRM lesion on the expression of $\alpha 4$-containing neurons in the NRM, rats received a single intra-NRM injection of 5,7-DHT, a serotonin neurotoxin. Immunohistochemical assessment of the expression of both the serotonin marker tryptophan hydroxylase and the $\alpha 4$ subunit of the nAChR was performed $30 \mathrm{~d}$ after 5,7-DHT (or PBS) treatment (Fig. 6). A similar pattern of immunostaining with regard to size and number of positive cells in the NRM was observed in a saline-treated rat, using antibodies against tryptophan hydroxylase (Fig. 6A) and the nAChR $\alpha 4$ subunit (Fig. $6 C$ ). Intra-NRM administration of 5,7-DHT $(3.7 \mathrm{nmol})$ almost completely reduced both tryptophan hydroxylase (Fig. 6B) and $\alpha 4$ (Fig. 6D) immunostaining, compared with the saline-treated control rat. However, staining using an antibody against the neurofilament protein NF-200, a neuronal marker, was observed in the NRM of both the PBS and 5,7-DHT-treated rats (data not shown). 

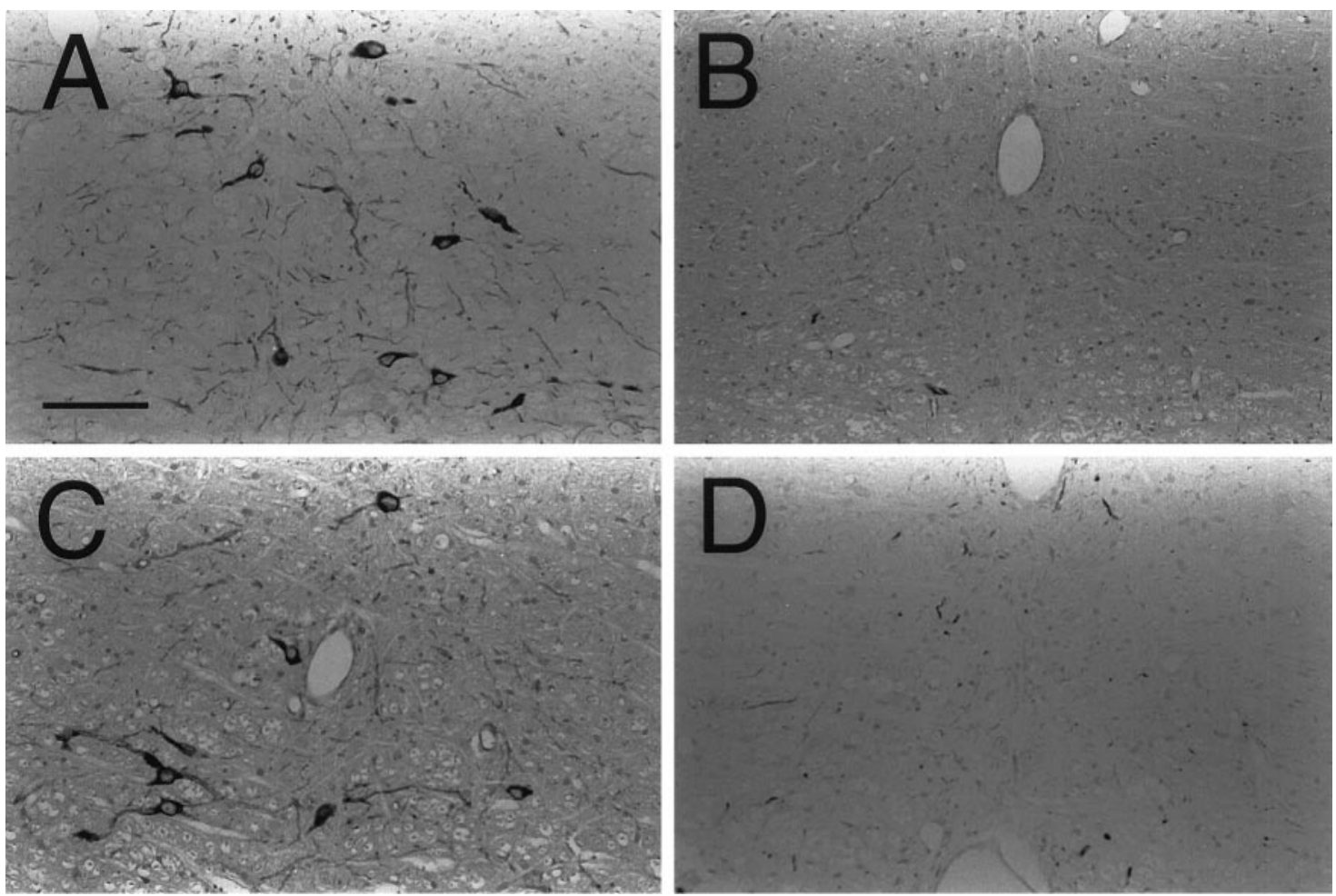

Figure 6. Photomicrographs of tryptophan hydroxylase and the $\alpha 4 \mathrm{nAChR}$ subunit in the NRM and the effects of a serotonergic neurotoxin. Expression of tryptophan hydroxylase is shown in the NRM of rats $30 \mathrm{~d}$ after either an intra-NRM injection of $0.3 \mu 1$ of PBS $(A)$ or 3.75 nmol of 5,7-DHT $(B)$ Expression of the $\alpha 4 \mathrm{nAChR}$ subunit is shown in the same animals again, $30 \mathrm{~d}$ after either a single intra-NRM injection of $0.3 \mu 1$ of PBS $(C)$ or 3.75 nmol of 5,7-DHT $(D)$. The serotonin neurotoxin resulted in almost a complete loss of serotonergic neurons and expression of $\alpha 4-$ containing nAChRs in the NRM. Scale bar, $100 \mu \mathrm{m}$.

\section{Double immunohistochemical labeling of tryptophan hydroxylase and $\alpha 4$}

To provide direct proof that $\alpha 4$-containing $\mathrm{nAChRs}$ are located on serotonergic neurons in the NRM, double immunohistochemical labeling of tryptophan hydroxylase and $\alpha 4$ was conducted. There was almost a complete overlap of immunostaining for tryptophan hydroxylase (Fig. 7A) compared with $\alpha 4$ (Fig. 7B) in neurons of the NRM. For control experiments (data not shown), the primary $\mathrm{Ab}$ against $\alpha 4$ during the second incubation was omitted; no $\alpha 4$ immunoreactivity was observed in these sections. Furthermore, reversing the order of the primary Ab incubations and replacing the anti-tryptophan hydroxylase with a polyclonal $\mathrm{Ab}$ against serotonin produced the same type of overlapping pattern of coexpression.

\section{DISCUSSION}

We previously demonstrated that intra-NRM administration of ABT-594 produced antinociception in models of acute and persistent pain (Curzon et al., 1997; Bannon et al., 1998). Results of this study further support a role for the NRM as one potential site of action for the antinociception produced by ABT-594. Systemic administration of ABT-594 produced a dose-dependent induction of Fos expression in the NRM that was blocked by systemic mecamylamine, but not hexamethonium. Immunohistochemical evaluation of the NRM revealed the presence of the nAChR $\alpha 4$ subunit, consistent with the possibility that ABT-594induced c-fos expression may be attributable to the direct activation of an $\alpha 4$-containing nAChR within the NRM. Finally, neurons in the NRM expressing $\alpha 4$ appear to be serotonergic, as evidenced by the loss of $\alpha 4$ expression after intra-NRM admin- istration of the serotonergic neurotoxin 5,7-DHT and, moreover, by the coexpression of tryptophan hydroxylase and $\alpha 4$ revealed by double-labeling experiments.

Induction of the immediate early gene c-fos can be triggered by various stimuli that produce depolarization (Morgan et al., 1987; Sagar et al., 1988; Morgan and Curran, 1991), including the agonist-receptor interaction resulting in the opening of a cation channel, as seen with activation of the nAChR (Greenberg et al., 1986). In this regard, drug-induced expression of c-fos has been used to identify neuronal activation in given brain nuclei (Sagar et al., 1988), thereby revealing potential sites of drug action. The ability of ABT-594 to produce a dose-dependent induction of c-fos expression in the NRM, as observed in these studies, suggests that the NRM may indeed be involved in antinociception produced by systemic administration of ABT-594. Furthermore, antagonism of ABT-594-induced NRM Fos by mecamylamine, but not hexamethonium, suggests that activation of the NRM, whether direct or indirect, requires activation of central nAChRs.

The in situ mapping strategy involving drug-induced Fos expression has been used with systemic administration of (-)nicotine. Ren and Sagar (1992) reported high levels of Fos immunostaining in the central visual pathways, including the superficial superior colliculus and the medial terminal nucleus as well as the interpeduncular nucleus, after a 60 min intravenous infusion of nicotine in rat. However, in areas known to contain high levels of nicotine-binding sites, such as the medial habenula, thalamus, substantia nigra, and ventral tegmental area (Clarke et al., 1985), nicotine-induced Fos expression was not observed. Moreover, they did not report c-fos induction in the NRM, as 




Figure 7. Photomicrographs of double labeling of tryptophan hydroxylase and the $\alpha 4 \mathrm{nAChR}$ subunit in the NRM. Using a fluoresceinconjugated secondary $\mathrm{Ab}$, tryptophan hydroxylase immunostaining $(A)$ shows almost complete overlap compared with the DAB chromogenic immunostaining of $\alpha 4$-containing neurons $(B)$ in the NRM of a salinetreated rat. Double-labeled neurons are indicated by arrows. Scale bar, $100 \mu \mathrm{m}$.

seen in the present study with ABT-594. This may suggest that ABT-594 activates nAChRs differentially from nicotine. Similarly, other studies demonstrating expression of Fos after systemic nicotine administration (Salminen et al., 1996; Pich et al., 1997) do not report activation of the NRM.

Despite the lack of reports that nicotine induces Fos expression in the NRM, (-)-nicotine injected into the NRM has been shown to produce antinociception in the rat hot-plate and tail-flick models of thermal pain (Iwamoto, 1991). We have shown that intra-NRM injection of ABT-594 in rats, consistent with studies using nicotine, produces antinociception in the hot-box test of thermal pain and the formalin test of persistent pain (Curzon et al., 1997). In these studies, systemic mecamylamine pretreatment or intra-NRM coinjection with mecamylamine blocked the antinociceptive effects of ABT-594 injected into the NRM, supporting an nAChR-dependent mechanism in the NRM. In contrast, intra-NRM administration of mecamylamine did not block antinociception produced by systemic injection of ABT-594. This result may suggest that nicotinic activation of the NRM is not required for antinociception produced by systemic ABT-594. However, other sites of action, in addition to the NRM, may be important in mediating the effects of systemic ABT-594 antinociception. In other studies from our laboratory, systemic injection of ABT-594 was shown to also increase Fos expression in the locus coeruleus (Bitner et al., 1997), a brainstem nucleus known to be involved in descending antinociceptive pathways (Yaksh, 1985). Another possible explanation for a lack of antagonism with intra-NRM mecamylamine could lie in the methodology of the experiment itself. The $0.3 \mu \mathrm{l}$ intra-NRM injection volume of mecamylamine used in the above experiment may not have been sufficient to antagonize all of the nAChRs throughout the entire NRM that would be activated by systemically administered ABT-594.

To examine the possibility that ABT-594 interacts directly with nAChRs in the NRM, immunohistochemical studies were conducted to determine whether the $\alpha 4 \mathrm{nAChR}$ subunit was expressed in the NRM. It has been suggested that the $\alpha 4 \beta 2$ subtype comprises at least $90 \%$ of neuronal nAChRs in brain (Flores et al., 1992; Lindstrom et al., 1995). Consistent with Fos mapping, studies using either radioligand autoradiography (Clarke et al., 1985), immunohistochemistry (Swanson et al., 1987), or in situ hybridization (Wada et al., 1989) have identified nAChRs in various brainstem nuclei, including the superior colliculus, the ventral tegmental area, and the interpeduncular nucleus. However, there have been no reports that specifically cite the presence or confirm the expression of nAChR-containing neurons in the NRM, as seen in the present study, and thus these data represent a novel finding.

To neurochemically characterize the type of neuron that may express $\alpha 4$, we assessed the effects of a serotonergic lesion on $\alpha 4$ immunostaining in the NRM. Intra-NRM injection of 5,7-DHT reduced the immunostaining of the rate-limiting enzyme of serotonin biosynthesis tryptophan hydroxylase as well as $\alpha 4$ immunostaining, indicating that serotonergic neurons in the NRM may express $\alpha 4$-containing nAChRs. This was directly confirmed by double-labeling experiments demonstrating that neurons in the NRM coexpress tryptophan hydroxylase and $\alpha 4$ protein.

Because of their descending projections to the dorsal horn of the spinal cord (Bowker et al., 1982), nAChR activation of serotonergic neurons in the NRM by ABT-594 may inhibit afferent nociceptive transmission at the level of the dorsal horn. In support of this proposed mechanism, the antinociceptive effect of systemically administered ABT-594 in a thermal model of pain was reduced by $62 \%$ in 5,7-DHT-treated rats, and ABT-594 injected directly into the NRM produced antinociception (Curzon et al., 1997). Similarly, others have demonstrated that either electrical stimulation (Oleson et al., 1978; Brodie and Proudfit, 1986) or pharmacological activation (Proudfit and Anderson, 1975; Iwamoto, 1991) of the NRM can produce antinociception in rats. Antinociception produced by intra-NRM injections of the nicotinic agonist $N$-methylcarbachol was shown to be blocked by intrathecal administration of the serotonin receptor antagonists LY53857 (5-HT $1 \mathrm{c} / 2)$ and $S$ - $(-)$-zacopride $\left(5-\mathrm{HT}_{3}\right)$ (Iwamoto and Marion, 1993), again supporting the possibility that nAChR agonists can stimulate serotonergic neurons in the NRM that descend to the spinal cord to bring about antinociception.

In conclusion, data from the present study provide further evidence consistent with the possibility that the antinociceptive action of the novel nAChR agonist ABT-594 may in part be mediated by activation of the NRM. Moreover, the involvement of the NRM in ABT-594 antinociception may be attributable to the activation of an $\alpha 4$-containing nAChR located on serotonergic neurons. However, it should be emphasized that the NRM 
may be only one of several nuclei that represent potential sites of antinociceptive action produced by ABT-594, and other subunitcontaining nAChRs besides, or in addition to, $\alpha 4$ may be involved. Similar studies, as reported here, involving ABT-594induced activation of other CNS nuclei as well as the mapping of additional $\mathrm{nAChR}$ subunits are ongoing.

\section{REFERENCES}

Bannon AW, Decker MW, Holladay MW, Curzon P, Donnelly-Roberts D, Puttfarcken PS, Bitner RS, Diaz A, Dickenson AH, Williams M, Arneric SP (1998) Broad spectrum, non-opioid analgesic activity by selective modulation of neuronal nicotinic acetylcholine receptors. Science 279:77-81.

Basbaum AI, Fields HL (1979) The origin of descending pathways in the dorsolateral funiculus of the spinal cord of the cat and rat: further studies on the anatomy of pain modulation. J Comp Neurol 187:513-532.

Bitner RS, Nikkel AL, Bannon AW, Arneric SP, Decker MW (1997) Supraspinal C-fos induction produced by a novel cholinergic channel modulator analgesic, ABT-594. Soc Neurosci Abstr 23:1200.

Bowker RM, Westlund KN, Sullivan MC, Coulter JD (1982) Organization of descending serotonergic projections to the spinal cord. Prog Brain Res 57:239-265.

Brodie MS, Proudfit HK (1986) Antinociception induced by local injections of carbachol into the nucleus raphe magnus in rats: alteration by intrathecal injection of monoaminergic antagonists. Brain Res 371:70-79.

Clarke PBS, Schwartz RD, Paul SM, Pert CP, Pert A (1985) Nicotinic binding in rat brain: autoradiographic comparison of $\left[{ }^{3} \mathrm{H}\right]$ acetylcholine, $\left[{ }^{3} \mathrm{H}\right]$ nicotine, and $\left[{ }^{125} \mathrm{I}\right]-\alpha$-bungarotoxin. J Neurosci 5:1307-1315.

Curzon P, Bitner RS, Nikkel AL, Bannon AW, Arneric SP, Decker MW (1997) Central mechanisms involved in ABT-594 antinociception. Soc Neurosci Abstr 23:1200.

Davis L, Pollock LJ, Stone, TT (1932) Visceral pain. Surg Gynecol Obstet 55:418-426.

Flores CM, Rogers SW, Pabreza LA, Wolfe BB, Kellar KJ (1992) A subtype of nicotinic cholinergic receptor in rat brain is composed of $\alpha 4$ and $\mathrm{B} 2$ subunits and is upregulated by chronic nicotine treatment. Mol Pharmacol 41:13-137.

Gogas KR, Presley RW, Levine JD, Basbaum AI (1991) The antinociceptive action of supraspinal opioids results from an increase in descending inhibitory control: correlation of nociceptive behavior and c-fos expression. Neuroscience 42:617-628.

Greenberg ME, Ziff EB, Greene LA (1986) Stimulation of neuronal acetylcholine receptors induces rapid gene transcription. Science 234:80-83.

Holladay MW, Wasicak JT, Lin N-H, He Y, Ryther KB, Bannon AW, Buckley MJ, Kim DJB, Decker MW, Anderson DJ, Campbell JE, Kuntzweiler TA, Donnelly-Roberts DL, Piattoni-Kaplan M, Briggs CA, Williams M, Arneric SP (1997) Identification, initial pharmacological evaluation, and structure-activity relationships of ABT-594 as a potent, orally active analgesic agent acting via neuronal nicotinic acetylcholine receptors. Soc Neurosci Abstr 23:1198.

Iwamoto ET (1991) Characterization of the antinociception induced by nicotine in the pedunculopontine tegmental nucleus and the nucleus raphe magnus. J Pharmacol Exp Ther 257:120-133.

Iwamoto ET, Marion L (1993) Adrenergic, serotonergic and cholinergic components of nicotinic antinociception in rats. J Pharmacol Exp Ther 265:777-789.

Jones SL, Light AR (1990) Electrical stimulation in the medullary nucleus raphe magnus inhibits noxious heat-evoked protein-like immunoreactivity in the rat lumbar spinal cord. Brain Res 530:335-338.

Lindstrom J, Anand R, Peng X, Gerzanich V, Wang F, Li Y (1995) Neuronal nicotinic receptor subtypes. Ann NY Acad Sci 757:100-116.

McGehee DS, Role LW (1995) Physiological diversity of nicotinic acetylcholine receptors expressed by vertebrate neurons. Annu Rev Physiol 57:521-546.

Millan MJ, Przewlocki R, Herz A (1980) A non-beta-endorphinergic adenohypophyseal mechanism is essential for an analgetic response to stress. Pain 8:343-353.

Morgan JI, Curran T (1991) Stimulus-transcription coupling in the nervous system: involvement of the inducible protooncogenes fos and jun. Annu Rev Neurosci 14:421-451.

Morgan JL, Cohen DR, Hempstead JL, Curan T (1987) Mapping patterns of c-fos expression in the central nervous system after seizure. Science 10:192-197.

Oleson TD, Twombly DA, Liebeskind JC (1978) Effects of painattenuating brain stimulation and morphine on electrical activity in the raphe nuclei of the awake rat. Pain 4:211-230.

Paxinos G, Watson C (1997) The rat brain in stereotaxic coordinates. San Diego: Academic.

Pich EM, Pagliusi SR, Tessari M, Talabot-Ayer D, Hooft van Huijsduijnen R, Chiamulera C (1997) Common neural substrates for the addictive properties of nicotine and cocaine. Science 275:83-86.

Proudfit HK, Anderson EG (1975) Morphine analgesia: blockade by raphe magnus lesions. Brain Res 98:612-618.

Ren T, Sagar SM (1992) Induction of c-fos immunostaining in the rat brain after the systemic administration of nicotine. Brain Res Bull 29:589-597.

Sagar SM, Sharp FR, Curan T (1988) Expression of c-fos protein in brain: metabolic mapping at the cellular level. Science 240:1328-1331.

Salminen O, Lahtinen S, Ahtee L (1996) Expression of Fos protein in various brain areas following acute nicotine and diazepam. Pharmacol Biochem Behav 54:241-248.

Sandkuhler J (1996) The organization and function of endogenous antinociceptive systems. Prog Neurobiol 50:49-81.

Sargent P (1993) The diversity of neuronal nicotinic acetylcholine receptors. Annu Rev Neurosci 16:403-443.

Sullivan JP, Bannon AW (1996) Epibatidine: pharmacological properties of a novel nicotinic acetylcholine receptor agonist and analgesic agent. CNS Drug Rev 2:21-39.

Swanson LW, Simmons DM, Whiting PJ, Lindstrom J (1987) Immunohistochemical localization of neuronal nicotinic receptors in the rodent central nervous system. J Neurosci 7:3334-3342.

Wada E, Wada K, Boulter J, Deneris E, Heinemann S, Patrick J, Swanson LW (1989) Distribution of alpha2, alpha3, alpha4, and beta2 neuronal nicotinic receptor subunit mRNAs in the central nervous system: a hybridization histochemical study in rat. J Comp Neurol 284:314-335.

Willis WD (1988) Anatomy and physiology of descending control of nociceptive responses of dorsal horn neurons: comprehensive review. In: Progress in brain research, Vol 77, Pain modulation (Fields HL, Besson JM, eds), pp 1-29. Amsterdam: Elsevier.

Yaksh TL (1985) Pharmacology of spinal adrenergic systems which modulate spinal nociceptive processing. Pharmacol Biochem Behav $22: 845-858$. 